\title{
Using a game for undergraduate global health students in the United States to practice applying ethical research principles
}

\author{
Sarah B. Rodriguez
}

\begin{abstract}
Global health programmes have become quite popular within universities in the United States. But despite the growth in undergraduate programming in global health, the training of American undergraduates to ensure they engage ethically when conducting research in a low- or middle-income country has not followed. I teach a course in global bioethics and developed the board game described in this article as a means of engaging students in active, peer-to-peer learning about ethical challenges, questions and concerns during the research planning process, while students are working abroad in unfamiliar contexts or upon return to their home university once their data collection is completed. The game is intended for students to apply what they learned regarding global bioethical practice.
\end{abstract}

\section{KEYWORDS}

educational games, global bioethics, global health, research ethics, undergraduate teaching

As many have noted, global health is now 'fashionable' in the United States, with philanthropies, governments and universities interested in the field (Brown 2008; Koplan et al. 2009). A central part of a commonly recognised definition of global health includes 'achieving equity in health for all people worldwide' (Koplan et al. 2009). In an effort to address what achieving equity in health means ethically, the field of global bioethics has recently emerged. Though a concise definition is still needed, global bioethical principles generally include a balance between respecting individuals and populations and include concepts from medical ethics (beneficence, non-maleficence), public health ethics (fairness) and human rights (respect for human dignity); core 
components include the principles of social justice and solidarity (Benatar et al. 2003; Kass 2001; Pinto and Upshur 2009; Stapleton et al. 2014).

There has been tremendous growth in the number of medical programmes within universities in the United States, many of which enable medical trainees to go abroad for a clinical rotation or to conduct research. This development has generated discussion about the ethics of medical trainees' activities abroad, including research (Crump et al. 2010; Crump and Sugarman 2008; Elit et al. 2011; Hanson et al. 2011; Melby et al. 2016; Nelson et al. 2010; Pinto and Upshur 2009). ${ }^{1}$ Despite a similar growth in undergraduate programming in global health, the training of American undergraduates in order to ensure they engage ethically when conducting research in a low- or middle-income country (LMIC) has not followed suit (Merson 2014). ${ }^{2}$ Though there are some parallel ethical concerns between medical students and undergraduate students conducting research in global health - including knowing the limits of their training and realising they are foremost conducting research as a learning experience - there are also some unique concerns when undergraduates from the United States seek to do global health research in a LMIC including, at a fundamental level, a lower level of medical knowledge and clinical capabilities.

Undergraduate students, like medical and other graduate students, are trainees, and, as such, need training in conducting ethical human research before embarking on research, regardless of where it is conducted. Moreover, based on anecdotal information from peers in the United States who teach undergraduates in global health, instructors often overestimate our students' understanding of what is ethical. Students, enthusiastic and wanting to help, only focus on the potential for their research, and rarely consider methodological or ethical problems. This was reflected in a recent analysis by Kearsley Stewart of a research project conducted by several American undergraduate students in East Africa, with Stewart identifying the need to enable students to be critically self-reflective, to understand their 'privileged research role' and to 'consider the potential consequences of their role and their presence in the field.' Students need to ask if their project used scarce resources wisely and, if so, 'was this the best project for them?' She challenged instructors to not send students off on a 'research safari' (Stewart 2013).

I teach a course in global bioethics and developed the game described below to enable my students to apply what they learned from the course to various situations presented in the game. As there are some parallel ethical concerns between medical and undergraduate students conducting research 
in global health, this game can be easily adapted for both medical students and other graduate students working in global health. Though this article reflects on a game used in a specific context, given that the scenarios presented within it concern questions about conception, methods and actions in research with human participants, it could conceivably be adapted or expanded for students regardless of where they are based or where they are doing their research.

\section{Situating the game}

An educational game is a teaching tool requiring student participation (Akl et al. 2010). Games are a method for students to work collaboratively on a problem that follows a determined set of rules and a goal; they are a means of promoting experiential learning (Anyanwu 2014). This game was designed to enable students to collaborate in synthesising and applying central components of the gaming experience - what they learned in the course to the real-world scenarios that appear in the game (Whitton 2012; Moseley and Whitton and 2012). The game promotes active engagement with the concepts presented in the classroom by having students apply them to realistic scenarios in a playful setting (Brookes and Moseley 2012). Whitton has articulated the importance of playful learning within higher education, in particular that it gives students a space to safely fail within an overall educational environment that places students under increased competitive pressure to not fail (Whitton 2018). Though Whitton acknowledges it may not create a safe space for all students, playful learning may provide for engaging collaboration among students (Whitton 2018).

This game was designed as a space for students to safely practice applying the ethical principles they learned in class to real-life scenarios in a space where their decisions do not have real-life implications. In this way, it reflects problem-based learning (PBL) methods. While PBL is not a specific education method, as Barrows noted, all PBL methods structure the instruction around a problem. Per Barrows taxonomy, this game is structured around the idea that '[e]ducation is most effective when it is undertaken in the context of future tasks' (Barrows 1986). Though not as deeply immersive as PBL, this game still draws on one of the concepts central to it: working in groups to solve a problem one could encounter in actual research (Hmelo-Silver 2004).

Games have been used in teaching at medical schools and in nursing schools on subjects from anatomy to the social determinants of health, 
though games have mostly concerned areas in clinical sciences (Akl et al. 2010; Akl et al. 2013; Anyanwu 2014; Reeve et al. 2008). ${ }^{3}$ To a lesser extent, games have also been used in medical and nursing schools as a means to teach ethics in a participatory manner (Lovett and Seedhouse 1990; Metcalf 2003; White and Davis 1987). As a method in undergraduate courses - or in medical or other graduate student courses - little has been written on the use of games within a global bioethics curriculum. ${ }^{4}$

The game is centred around problems students could encounter when doing research and is based on undergraduate global health research competencies (Hatfield et al. 2009; The Forum on Education Abroad 2013). It was inspired by 'The American Dream' game developed by Jennifer Yim while she was a graduate student at the University of Michigan. ${ }^{5}$ The students play the board game I developed at the end of the course, after spending several weeks considering global ethical research codes, in particular the Nuremberg Code - the first international code of medical research ethics created in 1946 in response to the horrors of the science conducted in Nazi-era Germany - and the Declaration of Helsinki, most recently revised in 2013, a set of internationally recognized ethical principles regarding biomedical research with human participants (Millum et al. 2013; Shuster 1997; World Medical Association 2013). Furthermore, they also learn about the core US bioethical principals of autonomy, informed consent, non-maleficence, and beneficence (Beauchamp and Childress 1979). In addition, students also engage with the ethical principles of social justice, solidarity, health as a human right, respect for cultural differences and for human dignity, together with the importance of being self-reflective regarding their roles and positions. During the class, students discuss how the principles play out in research by considering the importance and meanings of community engagement, collaborative research, sustainable research, working within existing health care structures, benefits to the community regarding the research, methods of providing information back to the community and potential downstream effects of research. The scenarios in the game enable students to apply these principles and their applications to solve the problems.

\section{Playing the game}

In order to play the game, I break up the class - typically containing twenty students - into four small groups with five students in each group. Each small group receives a dice, five different-coloured game pawns, a stack of 


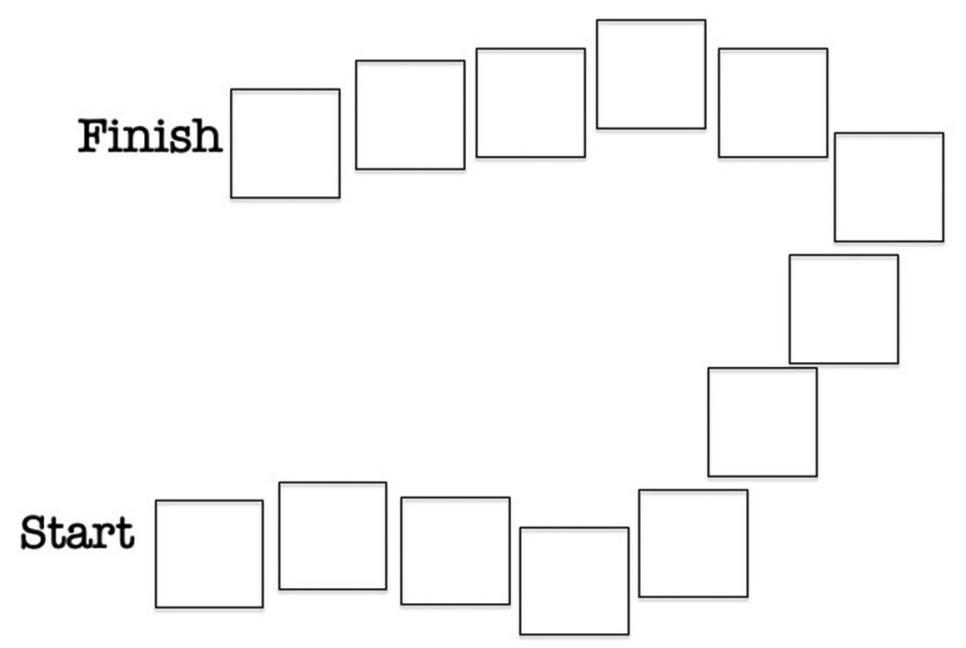

Figure 1. Game board.

scenarios printed on slips of paper and contained in an envelope and a game board [see Figure 1 for an illustration of the board used for the game]. The game board is a piece of standard white letter paper printed horizontally. A start box is drawn on the lower left corner with more boxes forming a slightly twisting path from the start box to a finish box in the upper right. In each team, the student with the highest roll of the dice goes first, and play moves in a counter-clockwise direction from the starting student. (The dice are not used again.)

All students place their game pawns on the start box. The first student draws a scenario card from the envelope and reads the scenario aloud. After sharing the scenario, the student follows the instructions given on the card, and places the card face down, either on the desk or in the middle of the game board. Each subsequent student follows suit, drawing a scenario card, reading it aloud, and following the card's instructions.

\section{Scenarios and themes in the game}

The scenarios are in no particular order. Most scenarios originally included instructions for the student on what to do with their pawn. The options for movement were forward, backward, return to start, and losing a turn. 
Scenarios with forward movement have in common that the student is using resources constructively by building upon and assessing their own and others' knowledge, developing an understanding and respect for where they propose to conduct their research and assessing and adjusting their proposed research to enable them to work within the community. Scenarios with forward movement include:

- before starting on your research proposal, you find a mentor at a university in the community where you are hoping to do research;

- after deciding on a research project, you read all you can about the community and the health care concerns in that community, adjusting your research question and project to fit with what you have read;

- your proposal observes and recognises local health care systems;

- your research proposal fits within your overall academic career, and includes prior coursework;

- the local university professor in the LMIC who is your mentor introduces you to people with whom you will conduct your research;

- after deciding on a research project and country, you contact two people at your university who have done extensive research in the country you hope to do research in to obtain their feedback on the feasibility of your proposed project and for advice on writing culturally appropriate consent forms;

- you contact a local NGO in the community where you are hoping to do research to ask for advice on research topics relevant to their community's needs.

All of these scenarios enabled a student to move forward one square. Only one scenario allowed a student to move more than one square: your local university professor mentor introduces you to a fellow undergraduate student, a resident of the LMIC community you are visiting, and you collaborate with this student on a research topic.

Though there were scenarios where a student advanced, in the majority of scenarios, the student moved backward - thus not advancing with their research. Scenarios with backward movement have in common the themes of poor planning or a lack of follow-through on the research. Some scenarios had students moving back one or two squares, such as: 
- you finish your research project and then do not follow up with your advisor in your home university;

- your local translator becomes ill, and you do not speak the local language;

- you finish your research project but do not follow up with the on-site coordinators/sponsors/collaborators in the LMIC where you conducted the research.

Some scenarios have the student returning to the start, and these scenarios have as a theme poor planning of the research proposal, suggesting an intervention for which the student is not trained, and a lack of respect for the host community. Scenarios with this outcome include:

- your research proposal proposes an intervention you have no training to conduct;

- when you meet with your home university faculty advisor, she states that you do not understand the culture where you want to do research sufficiently to accomplish the project and will not sign on as your primary faculty sponsor and mentor;

- you contact a local organisation in the community you hope to do your research in for ideas for research projects they would find helpful, but though they suggest three, you reject all of them and chose one they did not mention;

- your proposal shows you do not understand the fundamentals of research design.

Finally, several of the scenarios have the student losing a turn, representing a halt to their research to reconsider or refocus it. Scenarios that result in the loss of a turn fall under the common themes of poor planning, not being fully prepared to do the research or not fully understanding where you are proposing to do the research. Some of these scenarios include:

- you travel to a country but are unable to employ a translator;

- you arrive at your study location, only to discover it is a holiday week, and no one is available to meet with you;

- though you have research clearance from your university, you arrive in country without a research clearance from the appropriate research clearance board from the appropriate institution abroad. 
In addition to scenarios with specific movement directions, the game also includes scenarios requiring students to discuss and determine the student's next move. For example, one scenario reads 'during your research, one of your interviewees says they are very, very hungry. You buy this person flour, but word of this purchase gets out, and now everyone expects flour from you in exchange for their participation'. Another scenario reads, 'During the administration of your survey, you encounter a child in need of help, and you help this vulnerable child. However, word gets out about the help you offered, and others make life more difficult for this child'. In such scenarios, the student who drew the card needs to discuss how they would handle the situation they created, and then the students as a group decide whether the student should move forward, backward, or not at all, based on their answer.

Similarly, several scenarios ask 'what do you do?'. Once the student who drew the card responds, the group evaluates the response and determine whether the player should move forward or backward. Scenarios asking 'what do you do?' include:

- you are handing out a survey at a busy clinic and a person you are handing the survey to asks you for medical advice (assuming you are a medical student when you introduce yourself as a student) and you think you know the answer to the question;

- the local community group you are working with on a project they helped you create tells you that you will get better answers if you inform the people you are surveying you are a medical student, which you are not;

- you and a fellow student from your university are doing research in the same country in the same location, but your peer is asking questions you find to be shockingly inappropriate, ones you cannot imagine asking;

- you have research clearance from your university, and when you arrive in the country where you will be doing the research, you believe you have clearance from the local university, so you begin conducting your survey, but three weeks later, you receive a letter informing you have not been granted the research clearance from the local university;

- you find on the internet an NGO working on an issue you are interested in, and in the country where you would like to do your research, so you contact them and set up a project together, only to discover, when you arrive in the country, that they are being sued and considered a disreputable NGO in the community. 
The intention of the scenarios where students are instructed to discuss and decide the movement of the player who drew the card is to have the students engage with each other directly on how they would, or should, handle such scenarios. This means they have to directly apply what they have covered in class.

Since students typically see their research only in terms of the potential benefits that would result, and less about the potential difficulties or even harms they could inadvertently cause, this game ignites their awareness of ways their research could result in a negative experience, or even harm to themselves, the hosting community, particular research participants, their faculty mentors and/or a hosting NGO or university in the LMIC they are visiting. The scenarios where they need to discuss what should happen particularly engage with their use of the principles and the applications they learned in class.

\section{Reactions to the game}

I used this game in several global bioethics classes, but it was not until the fall of 2018 that I provided students with a post-game survey for them to evaluate it. The survey comprised of statements with possible answers along a five-level Likert scale (strongly agree, agree, neutral, disagree, strongly disagree) as well as two open questions. The survey was taken by two sections of the course, with forty-four students in both sections; forty-one took the survey. According to their responses regarding playing the game, an overwhelming majority of students ( 95 per cent) strongly agreed or agreed with the statement that the game was not too difficult to play and strongly disagreed or disagreed with the statement that they did not learn very much from playing it. In addition, the overwhelming majority of students strongly agreed or agreed that playing the game: helped them consider obstacles to research they had not considered ( 92 per cent); saw it as a beneficial means to explore complex bioethical concerns and issues regarding research in an LMIC (97 per cent); and felt it broadened their perspectives on the challenge regarding conducting research in an LMIC (87 per cent). A majority strongly agreed or agreed with the statement that they found they had a better understanding of the potential bioethical consequences of research in an LMIC after playing the game then before ( 65 per cent) and were exposed to parts of research they had not considered before playing (73 per cent). 
Two open-ended questions concluded the survey, and nearly all students provided some sort of feedback. In response to the first such question, 'overall, what did you like best about the research game exercise?', thirtynine provided a response. Many of the responses appreciated how, as the scenarios reflected actual or everyday scenarios that could occur, this enabled them to apply what they learned in class to real-life situations. Responses often focused on appreciating how the game enabled discussion and how it encouraged them to consider how they would respond to the scenario. Students also expressed benefiting from the discussion with their peers, especially noting the differences and similarities in how they responded to the scenario. Finally, students found the open-ended questions to be most useful in that it helped them to apply the concepts in class and solidify their application of ethical principles. Indeed, in response to the second openended question - 'overall, what did you like least about the research game exercise?' - of the thirty-four who responded, many expressed frustration at the frequent backward movement and/or loss of a turn, and instead wanted more of the scenarios without predetermined movements - they did not want to be told how to move without a discussion first.

Based on this response to the game, for the winter 2019 quarter I removed from all the scenarios a direction regarding movement to enable the students to first discuss. After this class played the game, I again handed out a survey. Forty students were enrolled in the winter quarter, and thirty-six took the survey. Though most of the responses were not as strong as they were in the fall, they were still quite similar. Again, an overwhelming majority (92 per cent) strongly agreed or agreed with the statement that the game was not too difficult to play and strongly disagreed or disagreed with the statement that they did not learn very much from playing it. Like their fall peers, the overwhelming majority strongly agreed or agreed that playing the game: helped them consider obstacles to research they had not considered (88 per cent); saw it as a beneficial means to explore complex bioethical concerns and issues regarding research in an LMIC (88 per cent); and felt it broadened their perspectives on the challenges regarding conducting research in an LMIC (86 per cent). A majority strongly agreed or agreed with the statement that they found they had a better understanding of the potential bioethical consequences of research in an LMIC after playing the game then before (64 per cent) and were exposed to parts of research they had not considered before playing (72 per cent). 
In response to the open-ended question asking them what they liked best about the game, all thirty-six students responded and, similar to the fall students, frequently noted how much they enjoyed talking about the scenarios and collaborating with their peers to come up with a response, especially when their peers answered differently. They also appreciated how they had to think about what they would do in a scenario and how the scenarios included ones they had not considered. Regarding their open-ended responses to what they liked least about the game, thirty-five students responded, with a handful of students noting some of the scenarios became redundant and a handful expressed frustration at having to deal with a mistake already made. A few students felt the activity was not a game at all, but rather simply discussion prompts (the unintended consequence, I think, of removing movement from the scenarios). Finally, a recurrent theme for some regarded responses and subsequent movement. Some complained of there being 'no clear answers,' one student suggested providing multiple answers to choose from with instructions on how to move based on the choice, and a handful of others felt the choice of movement was arbitrary.

\section{Next steps}

Considering the feedback from both groups of students, there are a few changes I will make before I teach this course and use this game again. First, the feedback regarding their not being 'clear answers' to some of the scenarios suggest I need to stress to an even greater degree throughout the quarter that sometimes in real-life scenarios there may not be one clear answer but, rather, a few better (or less bad) ones, and that they need to present an argument for why they are picking one response as the better (or least bad) choice out of the possibilities. Second, regarding the game itself, considering how many students, both in the fall and during the winter quarter, most appreciated the more complicated, nuanced, or ambiguous scenarios that asked 'what would you do?', I am going to create and add similar ones that enable more evaluation of the scenario and remove ones the students deemed as 'too easy', the ones that had already been essentially decided (the scenarios that used to come with a movement). Alongside this change, I am also going to make the directions clearer regarding when a player moves forward or backward by outlining that this decision is made based on how well the group thinks the player argued for why they made their decision, with forward movement in agreement and backward in disagreement. 


\section{Conclusion}

For the most part, students embraced the game in the manner it was intended: as an opportunity for them to apply what they learned in class. This is illustrated by their survey comments: 'I liked that each question was a concrete example of the theoretical bioethics we have been learning about'; 'the opportunity to think through what action you would actually take not just studying ethical concepts but seeing them in practice'; 'hearing the complexity of real-life scenarios and developing a solution (with the help of peers sometimes)'; and 'I felt like it was a good way to apply the overarching themes in the class with peers'. Their feedback suggests the game is a useful educational tool for students to apply what they have learned about conducting ethical human subject research through a game using real-life scenarios.

\section{Acknowledgments}

I want to thank Alecia Wartowski and the Change Makers programme at Northwestern University where I played 'The American Dream' game that inspired me to create this game. In addition, I want to thank Noelle Sullivan for providing substantive suggestions on an earlier draft of this article and for the useful comments I received following presentations of a version of this article at a Midwestern Consortium of Universities for Global Health Conference and at a Medical Humanities and Bioethics Montgomery Lecture at Northwestern University. I would also like to thank Juliet Sorenson for inviting me to have her students play the game during a session of her Health and Human Rights law course at Northwestern, and similarly thank Stacey Chamberlain for inviting me to do the same during a meeting of her Global Medicine Program at the University of Illinois at Chicago College of Medicine. Finally, thank you to the reviewers for their helpful comments. 
Sarah B. Rodriguez is a medical historian at Northwestern University. She is a Senior Lecturer in Global Health Studies in the Weinberg College of Arts and Sciences where she teaches Global Bioethics, the History of Reproductive Health and the History of Global Health. She is also a Lecturer in Medical Education in the Feinberg School of Medicine and in the Medical Humanities and Bioethics Graduate Program where she teaches the History of Medicine.

Email: srodriguez@northwestern.edu

\section{Notes}

1. See the online programme by Johns Hopkins and Stanford Universities, Ethical Challenges in Short-Term Global Health Training, http://ethicsandglobalhealth.org/ (accessed 13 January 2018).

2. For an outline of ethical considerations and guidelines for when undergraduates volunteer in global health work, see McCall and Iltis 2014.

3. Some studies have suggested that games are beneficial to medical students' learning skills and knowledge about clinical medicine, though two reviews of such evaluative studies concluded that the available evidence did not prove or disprove the benefit of games as an effective means of teaching medical students (Akl et al. 2013).

4. The only article I could find in the literature was that of Macer (2008).

5. 'The American Dream' I'm Not Racist Am I? (2017), http://www.notracistmovie.com/ workshops/the-american-dream/.

\section{References}

Akl, E. A., K. M. Sackett, W. S. Erdley, R. A. M. Mustafa, A. M. Fiander and C. Gabriel (2013), 'Educational games for health professionals', Cochrane Database Systematic Review, CD006411. https://doi.org/10.1002/14651858.CD006411.pub3.

Akl, E. A., R. W. Pretorius, K. Sackett, W. S. Erdley, P. S. Bhoopathi, Z. Alfarah et al. (2010), 'The effect of educational games on medical students' learning outcomes: A systematic review: BEME Guide No. 14', Medical Teacher 32, no. 1: 16-27. https:// doi.org/10.3109/01421590903473969.

Anyanwu, E. G. (2014), 'Anatomy adventure: A board game for enhancing understanding of anatomy', Anatomy and Science Education 7: 153-160. https://doi.org/10.1002/ ase.1389. 


\section{Sarah B. Rodriguez}

Barrows, H. S. (1986), 'A taxonomy of problem-based learning methods', Medical Education 20: 481-486. https://doi.org/10.1111/j.1365-2923.1986.tb01386.x.

Benatar, S. R., A. S. Daar and P.A. Singer (2003), 'Global health ethics: The rationale for mutual caring', International Affairs 79, no. 1: 107-138. https://doi.org/10.1111/ 1468-2346.00298.

Beauchamp, T. L. and J. F. Childress (1979), Principles of Biomedical Ethics (New York: Oxford University Press, 1979).

Brookes, S. and A. Moseley (2012), 'Authentic contextual games for learning,' in N. Whitton and A. Moseley (eds), Using Games to Enhance Learning and Teaching: A Beginner's Guide (New York: Routledge), 91-107.

Brown, D. (2008), 'For a Global Generation, Public Health is a Hot Field', Washington Post, 18 September.

Crump, J. A. and J. Sugarman (2008), 'Ethical considerations for short-term experiences by trainees in global health', JAMA: The Journal of the American Medical Association 300, no. 12: 1456-1458. https://doi.org/10.1001/jama.300.12.1456.

Crump, J., J. Sugarman, and the Working Group on Ethics Guidelines for Global Health Training (WEIGHT) (2010), 'Global health training: Ethics and best practice guidelines for training experiences in global health', American Journal of Tropical Medicine and Hygiene 83, no. 6: 1178-1182. https://doi.org/10.4269/ajtmh.2010.10-0527.

Elit, L., M. Hunt, L. Redwood-Campbell, J. Ranford, N. Adelson and L. Schwartz (2011), 'Ethical issues encountered by medical students during international health electives', Medical Education 45, no. 7: 704-711. https://doi.org/10.1111/ j.1365-2923.2011.03936.x.

Hanson, L., S. Harms, and K. Plamondon (2011), 'Undergraduate international medical electives: Some ethical and pedagogical considerations', Journal of Studies in International Education 15, no. 2: 171-185. https://doi.org/10.1177/1028315310365542.

Hatfield, J. M., K. G. Hecker and A. E. Jensen (2009), 'Building global health research competencies at the undergraduate level', Journal of Studies in International Education 13, no. 4: 509-521. https://doi.org/10.1177/1028315308329806.

Hmelo-Silver, C. E. (2004), 'Problem-based learning: What and how do students learn?', Educational Psychology Review 16, no. 3: 235-266. https://doi.org/10.1023/ B:EDPR.0000034022.16470.f3.

Kass, N. E. (2001), 'An ethics framework for public health', Journal of Public Health 91, no. 11: 1776-1782. https://doi.org/10.2105/ajph.91.11.1776.

Koplan, J. P., T. C. Bond, M. H. Merson et al. (2009), 'Towards a common definition of global health', Lancet 373, no. 9679: 1993-1995. https://doi.org/10.1016/ S0140-6736(09)60332-9.

Lovett, L. M. and D. Seedhouse (1990), 'An innovation in teaching ethics to medical students’, Medical Education 24: 37-41. https://doi.org/10.1111/j.1365-2923.1990 .tb02435.x. 
Macer, R. R. J. (2008), Moral Games for Teaching Bioethics, Haifa, Israel: UNESCO Chair in Bioethics.

McCall, D. and A. S. Iltis (2014), 'Health care voluntourism: Addressing ethical concerns of undergraduate student participation in global health volunteer work', HEC Forum 26, no. 4: 285-297. https://doi.org/10.1007/s10730-014-9243-7.

Melby, M. K., L. C. Loh, J. Evert, C. Prater, H. Lin and O. A. Khan (2016), 'Beyond medical "missions" to impact-driven short-term experiences in global health (STEGHS): Ethical principles to optimize community benefit and learner experience', Academic Medicine 9, no. 5: 633-638. https://doi.org/10.1097/ACM.0000000000001009.

Merson, M. H. (2014), 'University engagement in global health', New England Journal of Medicine 370: 1676-1678. https://doi.org/10.1056/NEJMp1401124.

Metcalf, B. L. (2003), 'Using gaming to help nursing students understand ethics', Journal of Nursing Education 42, no. 5: 212-215. https://doi.org/10.3928/ 0148-4834-20030501-07.

Millum, J., D. Wendler and E. J. Emanuel (2013), 'The 50th Anniversary of the Declaration of Helsinki: Progress but many remaining challenges', JAMA 310, no. 20: 2143-2144, https://doi.org/10.1001/jama.2013.281632.

Moseley, A. and Whitton, N. (2012), 'Introduction,' in N. Whitton and A. Moseley (eds), Using Games to Enhance Learning and Teaching: A Beginner's Guide (New York: Routledge), 3-8.

Nelson, B. D., R. Izadnegahdar, L. Hall and P. R. Lee (2010), 'Global health fellowships: A national, cross-disciplinary survey of U.S. training opportunities', Journal of Graduate Medical Education 4, no. 2:184-189. https://doi.org/10.4300/JGME-D-11-00214.1.

Pinto, A. D. and R. E. Upshur (2009), 'Global health ethics for students', Developing World Bioethics 9, no. 1: 1-10. https://doi.org/10.1111/j.1471-8847.2007.00209.x.

Reeve, K., K. Rossiter and C. Risdon (2008), 'The Last Straw! A board game on the social determinants of health', Medical Education 42: 1125-1126. https://doi.org/ 10.1111/j.1365-2923.2008.03215.x.

Shuster, E. (1997), 'Fifty years later: The significance of the Nuremberg Code', New England Journal of Medicine 337, no. 20: 1436-1440. https://doi.org/10.1056/ NEJM199711133372006.

Stapleton, G., P. Schröder-Bäck, U. Laaser, A. Meershoek and D. Popa (2014), Global health ethics: An introduction to prominent theories and relevant topics', Global Health Action 7. no. 1. https://doi.org/10.3402/gha.v7.23569.

Stewart, K. A. (2013), 'The undergraduate field-research experience in global health: Study abroad, service learning, professional training or "none of the above"?', Learning and Teaching 6, no. 2: 53-71. https://doi.org/10.3167/latiss.2013.060204.

The Forum on Education Abroad (2013), Guidelines for Undergraduate Research Abroad, https://forumea.org/resources/standards-of-good-practice/standards-guidelines/ undergraduate-research-abroad/. 


\section{Sarah B. Rodriguez}

White, G. B. and A. J. Davis (1987), 'Teaching ethics using games', Journal of Advanced Nursing 12, no. 5: 621-624. https://doi.org/10.1111/j.1365-2648.1987.tb03054.X.

Whitton, N. (2012), 'Good game design is good learning design', in N. Whitton and A. Moseley (eds), Using Games to Enhance Learning and Teaching: A Beginner's Guide (New York: Routledge), 9-18.

Whitton, N. (2018), 'Playful learning: Tools, techniques, and tactics', Research in Learning and Teaching 26. https://doi.org/10.25304/rlt.v26.2035.

Whitton, N., and A. Moseley (eds) (2012), Using Games to Enhance Learning and Teaching: A Beginner's Guide (New York: Routledge).

World Medical Association (2013), 'World Medical Association Declaration of Helsinki: Ethical principles for medical research involving human subjects', JAMA 310, no. 20: 2191-2194. https://doi.org/10.1001/jama.2013.281053. 